\title{
APPLICATION OF AHP METHOD IN SUPPORT OF DECISION-MAKING OF CIS SELECTION IN THE LAND FORCES OPERATIONS
}

\begin{abstract}
Saša M. Devetak ${ }^{* *}$
University of Defense in Belgrade, Military Academy

Samed M. Karović

University EDUCONS, Sremska Kamenica, Faculty of Applied Security

This paper describes application of AHP (Analytic Hierarchy Process) method as a method of multi-criteria decision-making in solving the problem of provision of the Communication and IT to the Land Forces in operations. Provision of the Communication and IT in operations is done by planning, organizing and using the adequate $\mathrm{CIS}$ (Communications and Information System).

This paper shows characteristics and capabilities of two CIS models. Besides definition of the problem, application procedure of AHP method has been described, selection criteria have been set and alternative models have been suggested. Expert Choice software package has been used in CIS model selection in the Land Forces operations.
\end{abstract}

Key Words: multi-criteria optimization, AHP method, CIS, model, military operation

\section{Introduction}

The success of military organizational systems management is based on continuous decision-making. Almost by rule, the decisions which have been made, have got a greater effect on the system in the nearer and farther future than at present. A decision is made in order to meet certain requirements - goals that are set up in the considered problem. A problem is often characterized by a larger number of criteria (the functions of goals, criteria) for decision-making, more alternatives (solutions) for selection and selection process of a single final solution. In such cases application of the methods of operational research comes specially to the foreground because multi-criteria approach represents the only way to realistically describe each particular problem. Within multi-criteria optimization AHP method can be successfully applied. It belongs to the methods of multi-attribute decision-making.

\footnotetext{
* This paper has been made on the basis of the research that was carried out within the scientific-research project under the number VA-DH/2-18-20 financed by the Ministry of Defence of the Republic of Serbia.

**sasa.devetak@va.mod.gov.rs
} 
This paper has used AHP method for solving the problem of CIS model selection in the Land Forces operations. The suggestion of possible CIS models in the Land Forces operations has been made by the analysis of tactical and technical characteristics of communications devices and systems and their capabilities. The criteria for model selection in operations have been defined by expert questionnaire and comparison of models in relation to criteria and their evaluation has been done. The results obtained by application of AHP method represent the elements to the decision-maker for CIS model selection in the Land Forces operations. Expert Choice software package has been used as a solution to the problem.

\section{CIS models in the Land Forces operations}

Characteristics of contemporary armed conflicts and military operations largely shape the manner of information usage. Information as a factor of an armed conflict is expressed like knowledge and needs for successful command at all levels. Processed and sent information in real time increases command efficiency, decreases duration of decision-making cycles at all levels and enables initiative and supremacy in an armed conflict. Linking all participants in military operations by electronic communications enables summary, delivery and display of relevant information. Thus, it is possible to create unique informational dimension of operational environment of military operations [1].

Provision of the Communication and IT in military operations is the process involving planning, organizing and using CIS for the sake of transmitting, protecting, electronic processing, storing and displaying information. Thereby, the necessary conditions for command functioning and management of engaged forces in military operations are created. Planning, organizing and using the Communication and IT provision contribute to finding a concrete CIS model, organizational structure is made and elements of a system in the area of an operation are placed in the technical and technological whole, communications and user services are maintained and used [2].

Therefore, the research of models of the Communication and IT provision in the Land Forces operations entails not only technological aspect of provision, but it has more radical purpose. To be more precise, analysis of the Communication and IT provision in combat operations can lead to CIS model of the Land Forces, which will enable efficiency and effectiveness of their functioning. This paper emphasizes shortly the characteristics of two possible CIS models in the Land Forces operations [3].

Model 1 is the integrated CIS according to the tactical study "Integrated signal system" and Programme of equipping the mobile component of the Serbian Armed Forces system with the communications devices. The model includes access and infrastructure levels organized into the subsystems of radio communication and radio-relay communication (cable component is optional). The Communication and IT units at all levels of command (the mobile component of the integrated CIS) form nodes for all types of communications at the access level (the Communications Centre of a battalion - signal section, brigade - signal platoon and the Land Forces Command - 1-2 companies of a signal battalion) and they are linked to nodes at the infrastructure level - the stationary components of the integrated CIS (stationary communications node and stationary com- 
munications centre). Radio communication is organized into networks according to command levels at a radio channel (the Land Forces - brigade, brigade - battalion and within a battalion) [4].

Radio-relay communication is organized into a ring structure linked to 2-3 stationary communications nodes and 2-3 stationary communications centres. Each access node of a battalion establishes two radio-relay directions up to $8 \mathrm{Mb} / \mathrm{s}$, that is the access node of a brigade and the Land Forces Command establishes three radio-relay directions up to $8 \mathrm{Mb} / \mathrm{s}$. Figure 1 shows an example of the possible topology of radio-relay network.

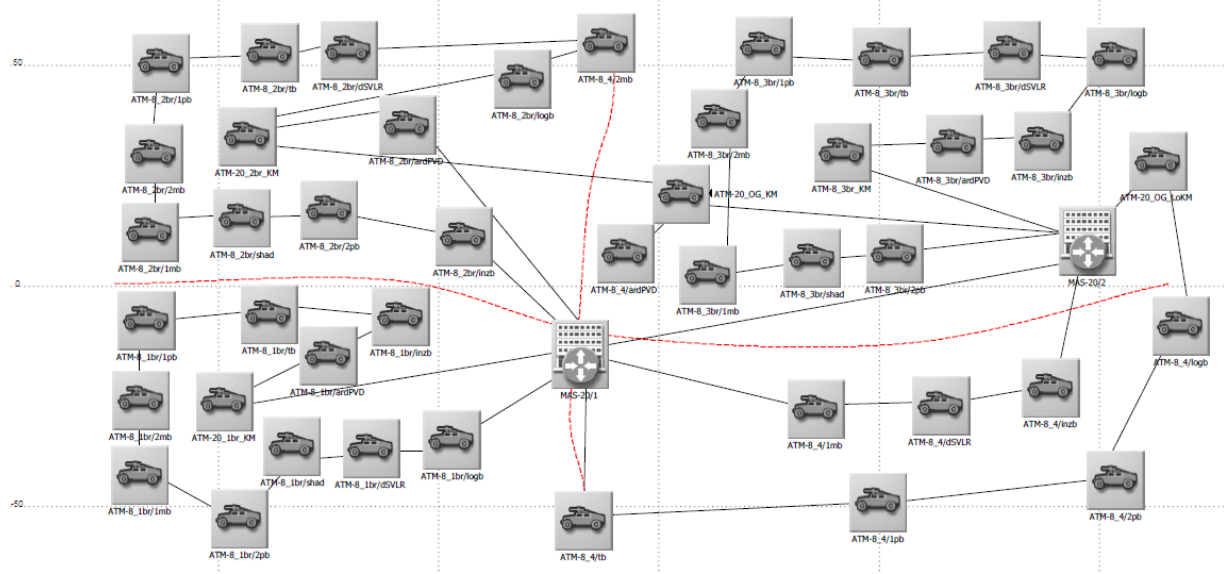

Figure 1 - Topology of CIS Model 1 (radio-relay communication subsystem)

Model 2 is a network concept, which represents a new type of the organizational CIS structure in the Land Forces operations. The network concept uses the same communications devices and it is organized into the subsystems of radio communication and radio-relay communication (cable component is optional). Radio communication subsystem is the basic CIS subsystem at a tactical level, and the only one in manoeuvre battalions.

A signal section of a battalion establishes exclusively radio communication at a battalion level and to a brigade level. Radio communication is organized into two networks at least with each participant from company to brigade (command network and data transmission network). At a brigade level concentration and integration of radio communication are carried out through access and network nodes of radio-relay communication subsystem (radio devices of high and very high frequency are integrated).

Radio-relay communication subsystem includes a network consisting of access and network nodes that are linked in a combined way (ring-star). Radio-relay communication subsystem is established by the Communication and IT units of brigades (signal companies) and the Land Forces (a company of a signal battalion). Having in mind that linking to the infrastructure level - stationary communications node is not necessary except pos- 
sibly an access point for the Land Forces Command in the area of a defensive operation, the model enables mobility of forces and their deployment to any territory (without communications infrastructure). Radio-relay communication network in a brigade zone consists of three netword nodes (each of them enables 4-6 radio-relay directions up to $8 \mathrm{Mb} / \mathrm{s}$ for interconnection of network and access nodes) and six access nodes (each of them enables a radio-relay direction up to $8 \mathrm{Mb} / \mathrm{s}$ for interconnection of battalions for support and a brigade). Network nodes are linked to the network nodes that are established in the Land Forces zones (a signal company of a signal battalion establishes them). Figure 2 shows the possible topology of radio-relay network [5].

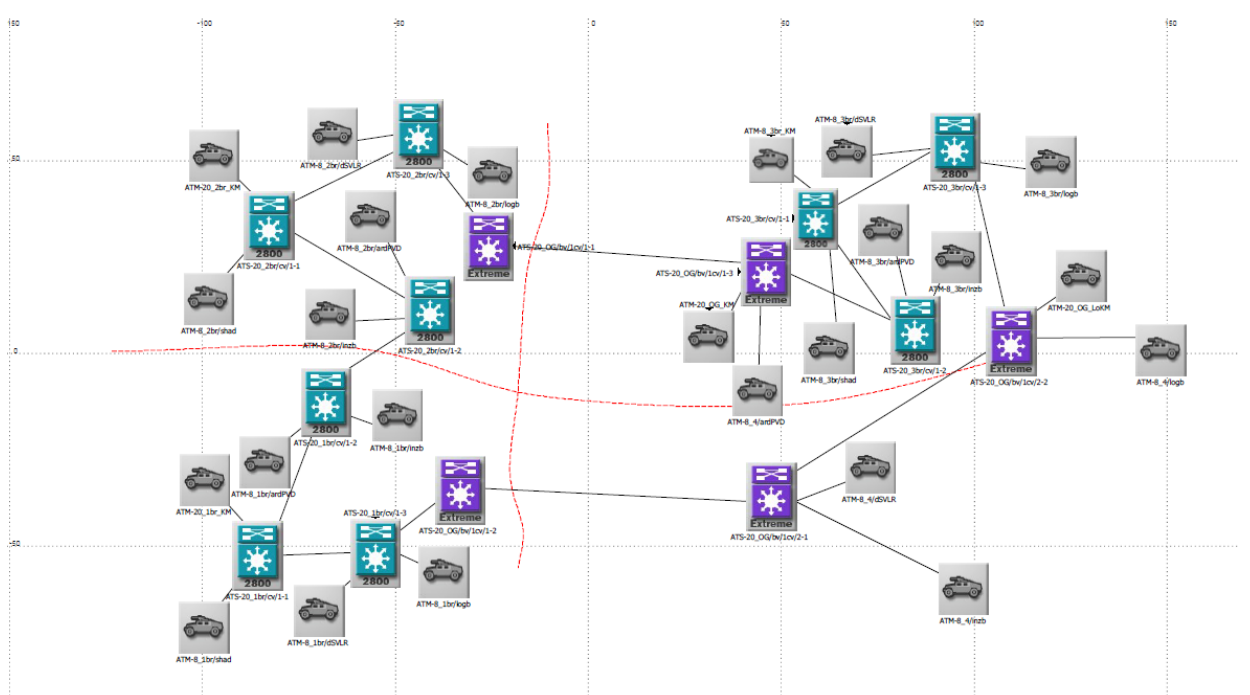

Figure 2 - Topology of CIS Model 2 (radio-relay communication subsystem)

The presented CIS models in the Land Forces operations represent two possible solutions characterized by certain features and capabilities of the system. Which of the mentioned models will function effectively in the Land Forces operations is the problem that should be solved by the method of multi-criteria decision-making.

\section{AHP method}

AHP is one of the most famous methods of scientific analysis of scenario and decision-making conducted by consistent evaluation of hierarchies, whose elements are goals, criteria, subcriteria and alternatives. The method was created by Thomas L. Saaty in 1980 [6] and it represents the tool that renders assistance to decision-makers in solving complex problems in decision-making. 
AHP belongs to the class of soft optimization methods. Basically, it is a specific tool for forming and analyzing decision-making hierarchy. Firstly, AHP method enables interactive structuring of a problem hierarchy as preparation of decision-making scenario, and then it enables pairwise evaluation of hierarchy elements (goals, criteria and alternatives) in the top-down direction. Finally, synthesis of all evaluations is done and priorities for all hierarchy elements are defined according to a rigorous mathematical model. The sum of priorities at each level of a hierarchy equals 1 , which allows the decision-maker to rank all elements in horizontal and vertical sense. AHP method enables interactive analysis of sensitivity of evaluation process to final ranks of hierarchy elements. Moreover, during evaluation of hierarchy elements until the end of the procedure and synthesis of results, consistency of decision-makers reasoning is checked and accuracy of obtained ranks of alternatives and criteria, as well as their priorities, is determined [7].

The validity of application of this method is seen in the existence of a greater number of criteria for CIS model selection, a greater number of suggested models, that is alternatives, simplicity and efficiency of application, as well as the original software developed for support to decision-making.

The method application is conducted in four phases [8]:

- problem structure, where it is necessary to decompose a problem, set a goal, criteria, subcriteria and alternatives. When it comes to methodological consideration, AHP method is a multi-criteria technique based on decomposing a complex problem into a hierarchy. A goal is at the top of a hierarchy whereas criteria, subcriteria and alternatives are at lower levels. As illustration, Picture 3 shows the hierarchy consisting of a goal, three criteria and four alternatives. A hierarchy does not have to be complete, for example, an element at some level does not have to be the criterion for all elements at a sublevel. Therefore, a hierarchy can be divided into subhierarchies that only have the top element in common;

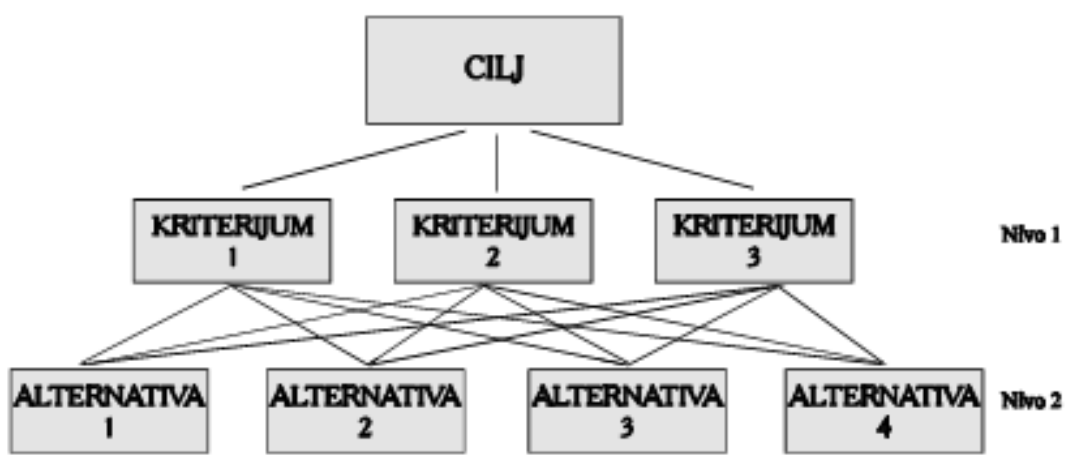

Picture 3 - Hierarchy example in AHP method

- data collection and their measurement, where the decision-maker assigns relative weights to criteria comparing them two at a time by using Saaty's nine-point scale presented in Table 1. In the final step of this process the adequate matrix of criteria judgement is obtained; 
Application of AHP method in support of decision-making of CIS selection in the Land Forces operations

Table 1 - Saaty's nine-point scale

\begin{tabular}{|c|l|}
\hline Scale & \multicolumn{1}{c|}{ Explanation/ranking } \\
\hline 9 & Absolutely strongly important/preferred \\
\hline 8 & Very to absolutely strongly important/preferred \\
\hline 7 & Very strongly to very important/preferred \\
\hline 6 & Strongly to very strongly \\
\hline 5 & Strongly more important/preferred \\
\hline 4 & Moderately to more strongly \\
\hline 3 & Moderately more important/preferred \\
\hline 2 & Equally to moderately more important \\
\hline 1 & Equally important/preferred \\
\hline 0,50 & Equally important/preferred to slightly less important/preferred \\
\hline 0,33 & Slightly less important/preferred \\
\hline 0,25 & Slightly to strongly less important/preferred \\
\hline 0,20 & Strongly less important/preferred \\
\hline 0,17 & Strongly to very strongly less important/preferred \\
\hline 0,14 & Very strongly less important/preferred \\
\hline 0,13 & Very strongly to absolutely less important/preferred \\
\hline 0,11 & Absolutely least important/preferred \\
\hline
\end{tabular}

- relative weight evaluation - the phase in which pairwise comparison matrix will "transfer" into problems of own values determination in order to get the normalized and single eigen vectors, as well as the weight of all attribute on each hierarchy level;

- problem resolution, which involves the establishment of the so-called composite normalized vector. After the vector of criteria activity layout is established, it is necessary to determine alternative importance in the model, within each criterion. The weight of each criterion is multiplied by the weight of the reviewed criterion, and these values are then summarized for each alternative separately. The result is the weight of the reviewed alternative within the model. The weight of all of the rest alternatives is calculated in the same way. After that, the final ranking of alternatives in the model is determined.

Considering that the alternative comparison is based on a subjective estimation by the decision maker, it requires constant monitoring in order to secure the required accuracy [9]. This method ensures that the evaluation consistency is monitored constantly in the alternative pairwise comparison procedure. The consistency index:

$$
\mathrm{Cl}=\left(\lambda_{\max }-\mathrm{n}\right) /(n-1)
$$

where:

$\lambda_{\max }$ - is the matrix Eigen value;

$\mathrm{n}-$ is the matrix size

calculates the consistency ratio $(\mathrm{CR})$

$$
C R=C l / R I \text {, }
$$

where $R l$ is the random consistency index (n size matrix consistency index of randomly generated pairwise comparison), for which Table 2 is used (with calculated values). 
Table 2 - Random consistency index values

\begin{tabular}{|c|c|c|c|c|c|c|c|c|c|c|}
\hline $\mathbf{n}$ & $\mathbf{1}$ & $\mathbf{2}$ & $\mathbf{3}$ & $\mathbf{4}$ & $\mathbf{5}$ & $\mathbf{6}$ & $\mathbf{7}$ & $\mathbf{8}$ & $\mathbf{9}$ & $\mathbf{1 0}$ \\
\hline $\mathrm{RI}$ & 0 & 0 & 0,52 & 0,89 & 1,11 & 1,25 & 1,35 & 1,40 & 1,45 & 1,49 \\
\hline
\end{tabular}

$\lambda_{\max }$ is the matrix Eigen value, whereas $n$ is the matrix size. Thereto, it is true that $\lambda \geq n$, and the difference $\lambda_{\max }-\mathrm{n}$ is used to measure the evaluation consistency. In case of inconsistency, if $\lambda_{\max }$ is closer to $\mathrm{n}$, the evaluation is more consistent. If $C R \leq 0,10$, the calculation of relative criteria importance (alternative priority) is considered acceptable [10].

\section{CIS model selection}

The function of a goal is defined by CIS model selection in the Land Forces operations. More efficient application of AHP method in a concrete case is enabled by use of the developed original software package Expert Choice from the class of decisionmaking support systems [11].

This paper describes two CIS models and they include alternatives:

A1 - Alternative 1 (Model 1);

A2 - Alternative 2 (Model 2).

Model selection will be done according to the set criteria:

$\mathrm{K} 1$ - Optimal resource engagement including minimum costs (efficiency);

K2 - Simple CIS structure;

$\mathrm{K} 3$ - CIS autonomy (independence from the stationary component or other communications device);

K4 - Ability to adapt to changes - mobility;

K5 - CIS capacities (number of simultaneous links, capacity and service availability);

$\mathrm{K} 6$ - CIS command and control $\left(\mathrm{C}^{2}\right)$;

$\mathrm{K} 7$ - Signal strength (continuity in communications);

K8 - CIS resistance and protection.

The presented criteria for model selection are set on the basis of the questionnaire done by competent personnel (experts ${ }^{1}$ ), and they are the result of knowledge, experience and resolution of the Communication and IT provision through complex operational tasks. A problem structure is shown in Graph 4.

\footnotetext{
${ }^{1}$ The experts, who have taken part in criteria selection are competent persons attending professional development for heads of the Communication units in battalions and brigades, company commanders and signal battalion commanding officers.
} 


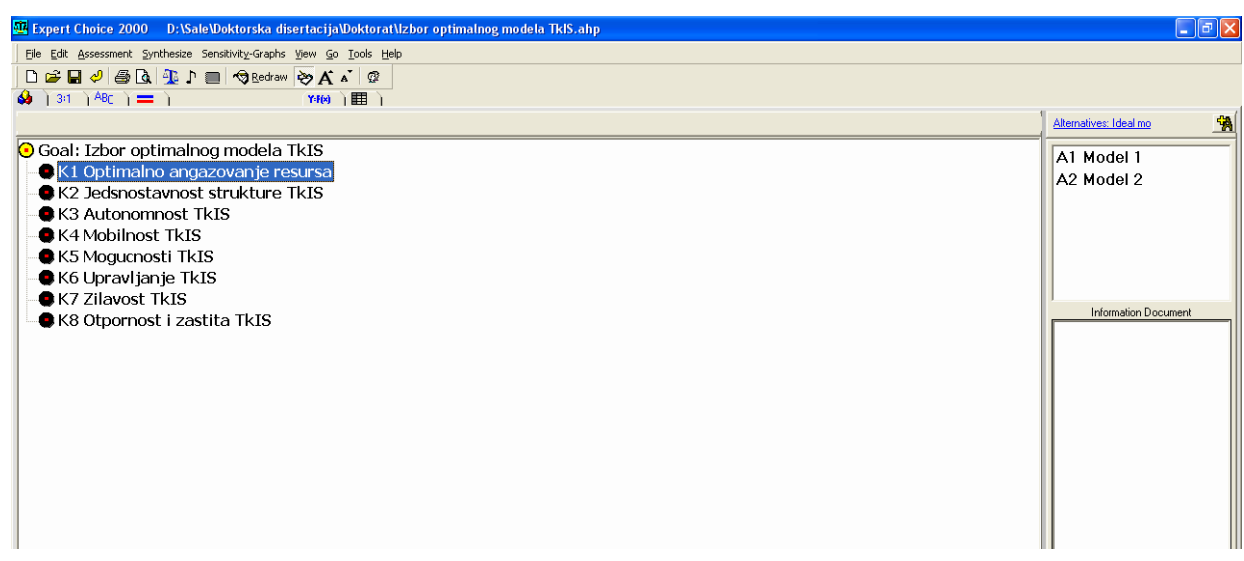

Graph 4 - Criteria and alternatives for model selection

Relative weights have been assigned to criteria by pairwise comparison done according to nine-point scale presented in Table 1. Processing data from the expert questionnaire has led to data on relative criteria weights. ${ }^{2}$

Picture 5 shows the procedure in software package Expert Choice.

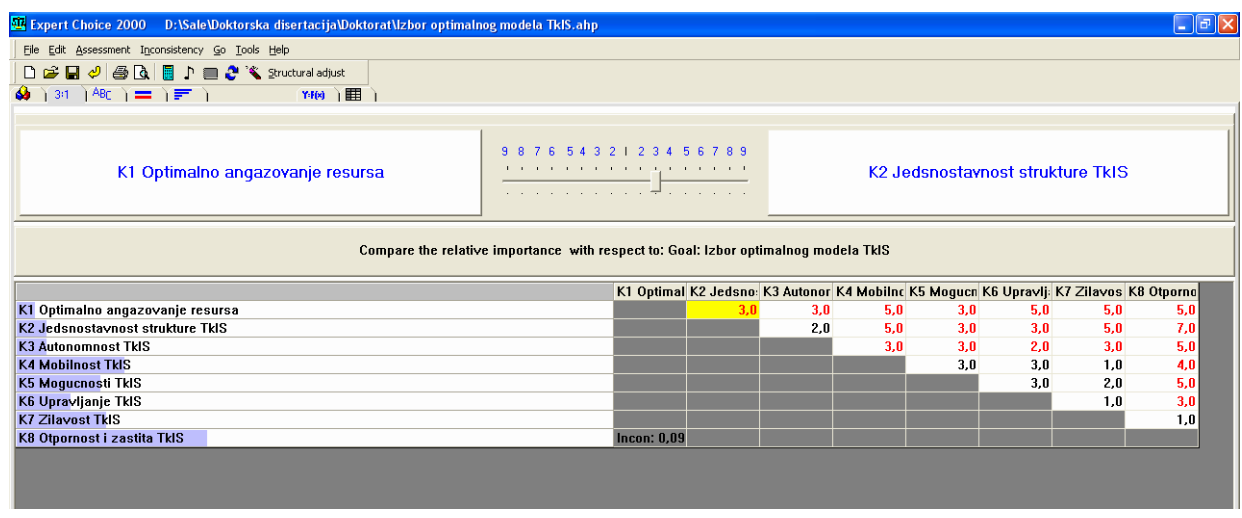

Picture 5 - Criteria evaluation matrix

From Picture 5 one could conclude that $\mathrm{CR}=0,09 \leq 0,1$, which is considered to be within the limits of the allowed.

Picture 6 presents priority importance in comparison with the set goal.

\footnotetext{
${ }^{2}$ The instrument that has been used for expert evaluation is the questionnaire.
} 


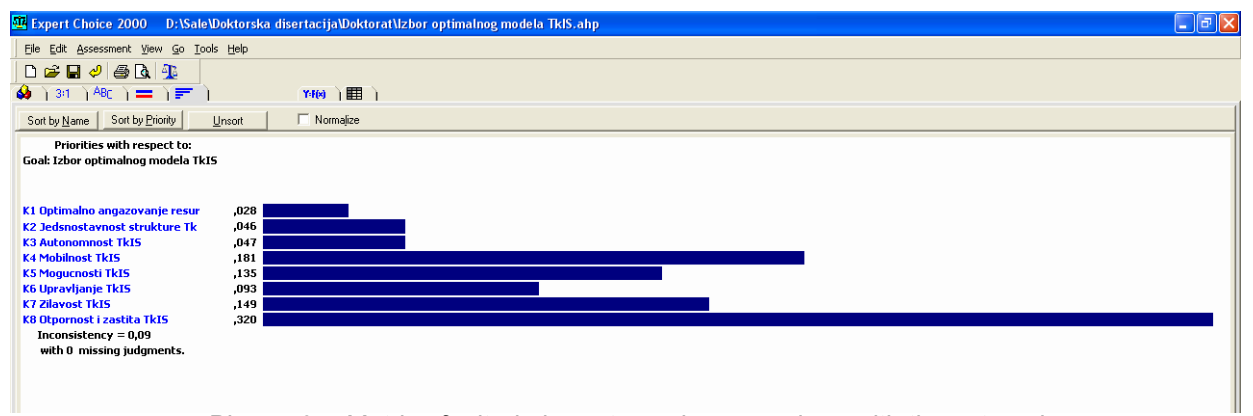

Picture 6 - Matrix of criteria importance in comparison with the set goal

The next step is alternative - model comparison for each set criteria separately. The comparison has been done on the basis of the conducted questionnaire with competent personnel (experts) according to nine-point scale presented in Table 1. The questionnaire results are presented in Table 3.

Table 3 - Questionnaire results of criteria comparison for given alternatives

\begin{tabular}{|l|c|c|}
\hline \multicolumn{1}{|c|}{ Criterion/alternative } & $\begin{array}{c}\text { Alternative 1 } \\
\text { (Model 1) }\end{array}$ & $\begin{array}{c}\text { Alternative 2 } \\
\text { (Model 2) }\end{array}$ \\
\hline K1 - Optimal resource engagement including minimum costs (efficiency) & - & 3 \\
\hline K2 - Simple CIS structure & 3 & - \\
\hline $\begin{array}{l}\text { K3 - CIS autonomy (independence from the stationary component or } \\
\text { other communications device) }\end{array}$ & - & 5 \\
\hline K4 - Ability to adapt to changes - mobility & - & 5 \\
\hline $\begin{array}{l}\text { K5 - CIS capacities (number of simultaneous links, capacity } \\
\text { and service availability) }\end{array}$ & 3 & - \\
\hline K6 - CIS command and control (C ${ }^{2}$ ) & - & 3 \\
\hline K7 - Signal strength (continuity in communications) & 3 & - \\
\hline K8 - CIS resistance and protection & - & 3 \\
\hline
\end{tabular}

Picture 7 presents alternative comparison for criterion $\mathrm{K} 1$.

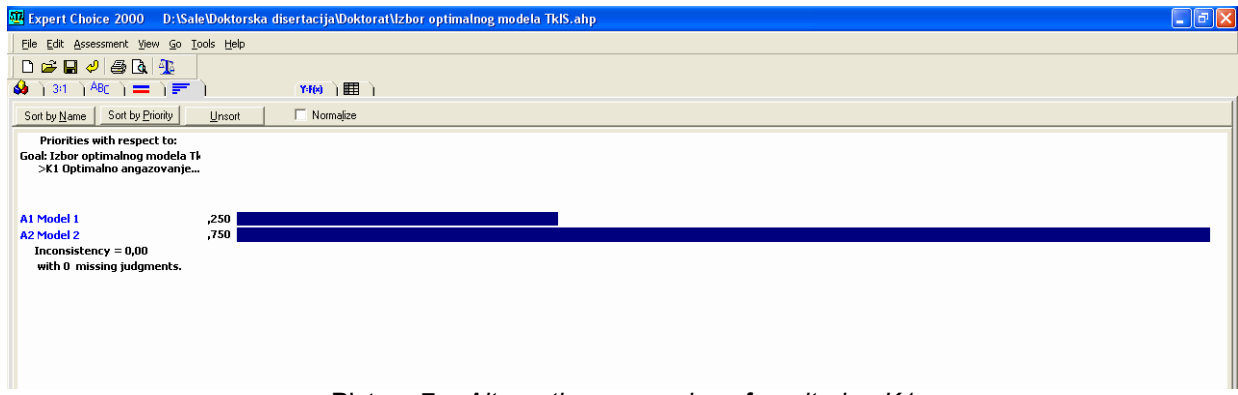

Picture 7 - Alternative comparison for criterion K1 
In the final step of this process the synthesis of the problem of CIS model selection in the Land Forces operations has been conducted and the obtained results have been summarized. Alternative 2 (Model 2), which has received a greater value is the solution of the problem. The final procedure of AHP method application is shown in Picture 8.

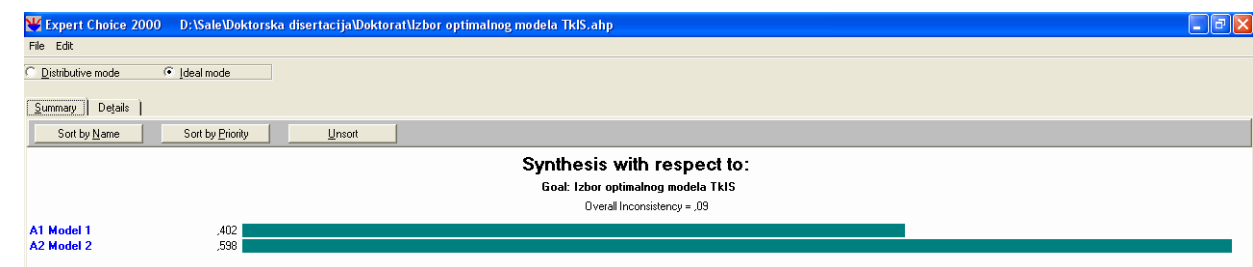

Picture 8 - Matrix of alternative importance in comparison with the set goal

Picture 9 shows comparative graphs of criteria and alternative importance in the analyzed model.

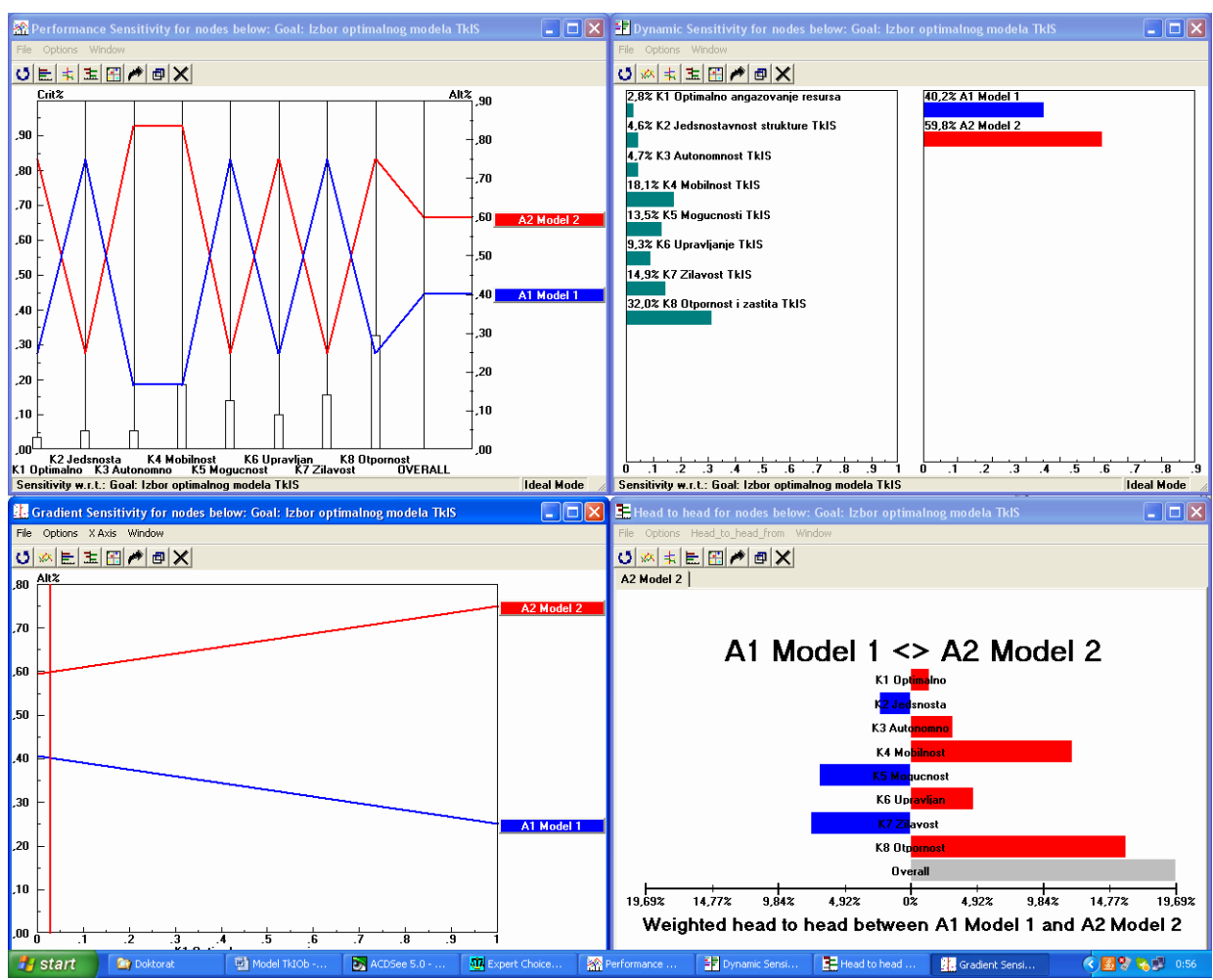

Picture 9 - Comparative graphs of criteria and alternative importance 
These graphs show sensitivity performance of the suggested alternatives in comparison with criteria for model selection, dynamic sensitivity with the values of own criteria and alternatives vectors, gradient alternative sensitivity and graph weight of the alternatives $A 1$ and $A 2$, which are in the foreground according to the set criteria. Besides its simplicity, the software solution is very practical and efficient when changing criteria or judging alternatives, that is during analysis of different approach to solving a problem.

\section{Conclusion}

Two CIS models have been created by the analysis of provision of the Communication and IT to the Land Forces, particularly CIS organization in operations and application of the complex of scientific methods. The main model has been made on the basis of the tactical study related to the equipping of the Serbian Armed Forces with integrated CIS whereas the network model is modification - specific organization of CIS carried out with the same Communication and IT devices. Both models have been used with radio communication and radio-relay communication subsystems and they are characterized by specific features from the aspect of the used Communication and IT devices and systems, the way of organization, capabilities of the Communication and IT capacities and services, mobility, simplicity of the structure, etc.

AHP method as one of the methods of multi-criteria optimization in solving the problem of CIS model selection in the Land Forces operations has been applied in this paper. In addition to definition of the problem, criteria and alternatives, the method application has been described. The model that represents an optimal solution for the set criteria has been selected by expert choice and evaluation of the set criteria, the comparison of created models (alternatives) and use of software package Expert Choice.

It can be concluded that considering the concrete problem two criteria are preferred CIS resistance and mobility. The software solution turned out to be very practical and efficient when searching for an optimal solution, that is analysis of different approach to solving a problem. The selected CIS model would render an adequate basis for provision of the Communication and IT to the Land Forces in operations.

In the context of support to decision-making, by AHP application the solution was found including the network model, which would meet all significant elements of efficient and effective functioning in the Land Forces operations. One should have in mind that the tool offers only a possible solution, but the final decision is made by the decision-maker, who remains the key factor in solving the functioning of the Communication and IT provision in operations.

\section{References}

[1] Doktrina telekomunikaciono-informatičkog obezbeđenja. Beograd: Medija centar „Odbrana", 2012.

[2] Devetak, Saša i Samed Karović. „Telekomunikaciono-informatičko obezbeđenje u operacijama". Vojno delo 6/2016, str. 123-135. DOI: 10.5937/vojdelo1606123D.

[3] Devetak, Saša, Samed Karović i Miroslav Terzić. „An approach in the analysis of communication-information system model in military operation". Vojno delo 4/2017, str. 123-135. DOI: 10.5937/vojdelo1704077D. 
[4] Taktička studija Integrisani sistem veza VS. Beograd: Uprava za telekomunikacije i informatiku GŠ VS, 2006.

[5] Devetak, Saša. Model telekomunikaciono-informatičkog obezbeđenja snaga Kopnene vojske u odbrambenoj operaciji. Doktorska disertacija. Beograd: Univerzitet odbrane, Vojna akademija, Beograd, 2016.

[6] Saaty. T. L.: Analytic hierarchy process, McGraw-Hill, New York, 1980.

[7] Čupić, Milutin i Milija Suković. Višekriterijumsko odlučivanje - Metode i primeri. Beograd: Univerzitet Braća Karić, 1995.

[8] Nikolić, llija i Siniša Borović. Višekriterijumska optimizacija. Beograd: Centar vojnih škola VJ, 1996

[9] Samanta, B. \& Mukherjee, S. K. Selection of opencast mining equipment by a multicriteria decision-making process. Australia: Institute of Mining and Metallurgy, 2002.

[10] Devetak, Saša i Miroslav Terzić. „Primena metode analitičkih hijerarhijskih procesa u izboru optimalnog taktičkog radio sistema”, Vojnotehnički glasnik 3/2011, str. 161-176.

[11] http://expertchoice.com 